\title{
DOES FRAMING AFFECT RISK ATTITUDE? EXPERIMENTAL EVIDENCE FROM CREDIT MARKET
}

\begin{abstract}
Dmitry Vladimirovich Burakov
Financial University Under the Government of Russian Federation, Leningradsky Prospect, 49, 125993, Moscow, Russia

Received 2013-12-11; Revised 2013-12-21; Accepted 2014-01-02

ABSTRACT

In this article we study the effect of framing on the attitude of lenders toward risk over a credit cycle and also review potential causes of negative framing when making decisions. Using an experimental setting, we present evidence of frame of losses' significant impact on willingness to accept credit risk: In comparison with frame of gains, willingness to accept credit risk increases from $29 \%$ in frame of gains up to $77 \%$ in frame of losses. Among the main reasons leading to a shift in frames, changes in bargaining power and conflict of interests are proposed. Admitting the existence of negative framing in credit market helps explaining duration of credit crunches and excessive risk taking during the upward phases of credit cycle.
\end{abstract}

Keywords: Credit Cycle, Credit Dynamics, Credit Risk, Credit Market, Framing Effect, Bounded Rationality

\section{INTRODUCTION}

Most conventional (exogenous) models of a credit cycle are built on the assumption of fully rational behavior of economic agents (Yahya and Halaj, 2012). It's stated, as a consequence, that risk assessment by creditors is difficult or impossible due to credit market imperfections arising from uncertainty and information asymmetry. Moreover, cases of conscious, boundedly rational excessive risk taking by banks don't fit well with the underlying assumptions of such models (Geanakoplos, 2010; Pulakkazhy and Balan, 2013; Murugesan and Shanmugam, 2013).

On the other hand, models of endogenous credit cycles take into account bounded rationality of decision makers either through the emotions' channel (Boulaalam et al., 2013), or through the experience channel (Berger and Udell, 2004; Rotheli, 2012). First consider credit cycle as a process of changes in credit risk attitude by bankers under the impact of "waves of optimism and pessimism" in Pigouvian sense. Good times serve as a basis to a credit expansion, which inevitably becomes excessive because of optimistic bias. Due to the onset of some shock event, accumulated risks are realized and credit crunch starts. This phase of a cycle is accompanied by a reduction in the availability of credit and increased pessimistic market sentiment.

The latter believe credit cycle to be a somewhat different phenomenon. According to experience based models, credit cycle, as a change in quantity and quality of loans granted, is driven by another reference pointexperience of key decision makers. The further the distance between the past crisis and the present state of the market, the higher the likelihood of credit risks underestimation. Rotheli (2012) According to institutional memory hypothesis, the less experience key decision makers have, the higher the likelihood of credit risks underestimation (Berger and Udell, 2004).

Unfortunately, only in several models of a credit cycle it's assumed that creditors take excessive risks consciously. Although another assumption exists: In the context of high competitive pressure, necessity of maintaining the market share, maintaining the average market rate of share's price, commercial banks have to consciously reduce lending standards and take on excessive credit risk (Haldane et al., 2010). In the model of cumulative credit cycle (Haldane et al., 2010) a certain role is assigned to framing effect: In the context of fierce competition when making decisions on approval of credit applications, a change of perception occurs. Instead of 
gains' estimation arising from the issuance of a loan, evaluation of losses from the denial of credit is perceived. According to prospect theory, authors of cumulative credit cycle model interpret it as a consequence of coordination failures, where lenders' excessive risk-taking is associated with the desire to avoid certain losses right now, than incur possible, but larger losses later.

However, cumulative model of credit cycle has a number of disadvantages: First, assumed role of negative framing has no empirical argumentation; secondly, an explanation of a credit cycle through frame of losses can't claim to be complete, due to the fact that not all credit markets are characterized by tough competition and dependence on highly elastic yield function of investors, leading to formation of negative framing. However, undoubtedly, the change of frames has a significant impact on the development of the credit cycle in general and on the change in the willingness to accept credit risk in particular.

Given the highlighted shortcomings, we try to enrich the existing views on the credit cycle by defining the role of framing in bank credit market. To achieve the abovementioned goals we have set the following tasks: (1) to prove experimentally the existence of the relationship between frame of losses and willingness of creditors to accept risks; (2) to assess the scale of negative frame's impact on credit risk attitude; (3) to determine the place of frame of losses as a factor of credit cyclicity; (4) to identify and review possible causes of negative framing in the credit market.

\section{METHODOLOGY}

To achieve the abovementioned goals, we used an experimental setting, developed earlier and modified according to goals of this study, (Burakov, 2011; 2012; 2013) that allowed us to reproduce the main characteristics of a credit market on the one hand and to identify creditors' attitude toward risk in frame of gains as well as in frame of losses.

Using the achievements of behavioral economics (Kahneman and Tversky, 2000), we introduced the credit market, as the number of subjects (153 subjects participated in experiments), committing a choice under risk. To display the features of the credit market in frames of gains and losses we designed the following standard context.

"Get the sum N1 with probability p1 now and sum $\mathrm{N} 2$ in 3 months and with probability p2 get nothing".

To display the features of the credit market in frame of gains, we presented the following choice setting:

- A sure win of \$100 now and \$200 in 3 months
- $60 \%$ chance to win $\$ 300$ now and $\$ 500$ in 3 months and $40 \%$ chance to win nothing

Introducing the condition of certainty, we mean the desire of creditors to pseudocertainty when granting loans (Burakov, 2013). For example, this applies to regular borrowers.

To display the features of the credit market in frame of losses, we simply changed gains into losses:

- A sure loss of $\$ 100$ now and $\$ 300$ in 3 months

- $60 \%$ chance to loss $\$ 500$ in 3 months and $40 \%$ chance to lose nothing

The sum of losses from non-issuance of the loan is increased compared with frame of gains in connection with the fact that the creditor loses not only the profit from loans, but also bears the losses associated with a decrease in the market value of his shares. To display the dynamics of credit we used a 15 rounds experiment. After 13 rounds we introduced a shocking event leading to the growth of Non-Performing Loans (NPL) and quantity of losses that a creditor will incur for sure. We asked the participants to answer the following question:

"In the period of the worsening conjuncture on the market, the average probability of default on the loan has increased from 40 to $80 \%$. Are you ready to grant a loan to the borrower, if his percent of loans defaulted equals $2 \%$ ?"

For participants committing choice in frame of gains, the context was slightly changed:

"in the period of the worsening conjuncture on the market, the likelihood of repayment of loans on average reduced from 60 to $20 \%$. Are you ready to grant a loan to the borrower, if his percent of return on loaned funds equals $98 \%$ ?"

\section{THEORETICAL BACKGROUND}

\subsection{Underlying Assumptions}

In this study, using experimental methods, we try to strengthen theoretical principles of framing effect and its role in credit institutions' activities. Given the importance of bounded rationality in the functioning of markets (in particular, the credit market), we propose to introduce a number of assumptions, which allow to enforce explanatory power of existing credit cycle models. Firstly, we assume, following the model of cumulative credit cycle, that framing effect has a significant impact on lenders' attitude toward credit risk. 
This assumption is based on principles of prospect theory, (Kahneman and Tversky, 2000) regarding differences in subjects' risk attitude, depending on the perception of the outcome as a loss or a gain. Secondly, we assume that bankers, committing a choice in frame of losses, are more inclined to take excessive risks. Thirdly, we assume that negative framing has a significant impact on the credit cycle: Willingness to accept credit risk during the upward phases, increases more than in frame of gains; while during the downward phases, willingness to accept credit risk is substantially less than in frame of gains. Similar views can be found in the model of boundedly rational banks by Marti (1996), describing credit crunch phase of the cycle. However, in contrast to the model of Marti, we offer to explain the duration of credit crunch through cognitive channel of prospect theory. Fourthly, even taking into account the importance of the framing effect in explaining credit dynamics, it should not be considered a fundamental factor and especially the source, origin of credit cyclicity. Framing acts, in our understanding, as a kind of a multiplier, which fosters fluctuations in the dynamics of credit risk, at the same time being a result of many interacting market forces. In this case, defining the role of framing in excess credit supply depends on the state of the market and the ratio of high and low quality borrowers. This relation is not fixed and stable and varies from economy to economy; depends on the degree of development, on the quality of institutions, on level of competitive pressure in the market and many other factors. At the same time, exogenous factors can also lead to periods of a credit crunch.

In this regard, we believe that the model of cumulative credit cycle based on frame of losses and reinforced with coordination failures of various types (herding behavior, winner's curse and conflict of interests), is a kind of endogenous models of credit cycles and has insufficient descriptive and explanatory power.

\subsection{Review of Possible Causes of Negative Framing in Credit Market}

Well-known expression of $\mathrm{Ch}$. Prince, CEO of Citigroup, says "When the music stops, in terms of liquidity, things will be complicated. But as long as the music is playing, you've got to get up and dance. We're still dancing." Indeed, there was s a lot of statistical and empirical evidence, which pointed to significant overheat of credit markets in developed countries before the Great Recession. The main question concerning the shift of frames in the credit market, can be stated in the following way: "What leads lenders to perceive the granting of a loan as a necessity for survival and not as a source of income?"
Before we go on to review the current versions of the answer to this question, it is worth noting that, in our opinion, a change in framing is, first of all, a result of a shift in the bargaining power from creditor to other counterparties. In institutionally undeveloped countries (e.g., rent-seeking economies) or developing economies, the rules of the game in the credit market are set by creditors, in developed and rapidly developing countries the rules of the game are dictated by the borrowers and investors (especially in countries with developed financial markets).

Modern models of credit cycles describe a large number of factors promoting excessive risk taking. The main and most frequently mentioned factor for developed countries is a conflict of interest in different manifestations. The most significant of them, resulting in strategies of maintaining a share's market price, compensation schemes, encouraging fixation of shortterm results, is the conflict of bank's management and investors (shareholders and bondholders). The logic of this conflict is spoken as follows: In the conditions of fierce competition and high elasticity of bank investors' yield function, the managers have to increase the volume of loans granted (given a limited number of high quality borrowers) in order to maintain profitability indicators, which form the price of bank shares. If the manager fails to achieve the average or above the average return, investors will take their money from the bank and put them into more liquid assets (for example, buy competitors' shares). This will lead to a decrease in market price of bank shares and, subsequently, to the reduction in market niche and opportunities to generate profit Haldane et al. (2010). Another variation of this conflict is based on the so-called reputational concerns Rajan (1994). In this model the reason for increased risk taking is stated not through the high elasticity of investors' yield function, but is correlated with the high elasticity of the labor market for bank personnel. If executives will not pursue short-term fixation of profits, they are at risk, on the one hand, of a loss of income in the form of bonus payments and on the other, of finding a high-payed job in the future due to deterioration of their reputation.

Another variation of this conflict of interests applies to relationship with borrowers. Ruckes (2004) in conditions of a rigid competition and the need of maintaining a market share, information asymmetry gives rise to the so-called winner's curse. In the framework of this effect it is assumed that the lack of information about the quality of the borrower as a factor reducing readiness for accepting credit risk is compensated by the perception of expected losses in income (loss of opportunity) from this 
borrower. Winner's curse also enhances credit risk acceptance rate in negative framing.

Another quite common factor is the high elasticity of demand for credit, supported by high elasticity of investors' yield function. In the framework of this effect, the denial of a loan application brings the borrower to the other bank, which, in turn, reduces the potential income of the first bank and the ability to support market price of its' shares at the level accepted on the market.

\section{RESULTS}

The results of carried out experimental researches confirm our hypothesis.

Firstly, we confirmed the position, according to which the attitude toward risk and, in particular, toward credit risk depends on framing (Table 1). Thus, we partially reaffirm the propositions of model of cumulative credit cycles: The perception of decision made in frame of losses really enhances the acceptance of credit risk that may be considered as a factor of credit cycle's amplification. Also, this result is consistent with previous studies of behavioral economists on the impact of framing on the attitude toward risk.

Secondly, the introduction of a negative shock in different frames after 13 rounds also reinforces our view of the importance of framing for willingness to accept credit risk. Average readiness to grant a loan during bad conjuncture is higher in subjects perceiving choice in frame of gains. For lenders operating in frame of losses, willingness to lend funds in the given conditions is reduced even more. Figure 1 and 2 thus confirms our thesis about possible use of framing effect as a proof of the credit crunch duration.

Thirdly, these results serve as a direct argument in favor of prospect theory: Framing can be identified as one of reference points used by decision-makers.

Choice in frame of losses is actually characterized by higher levels of risk taking, while in frame of gains risk taking solely depends on relative level of outcome.

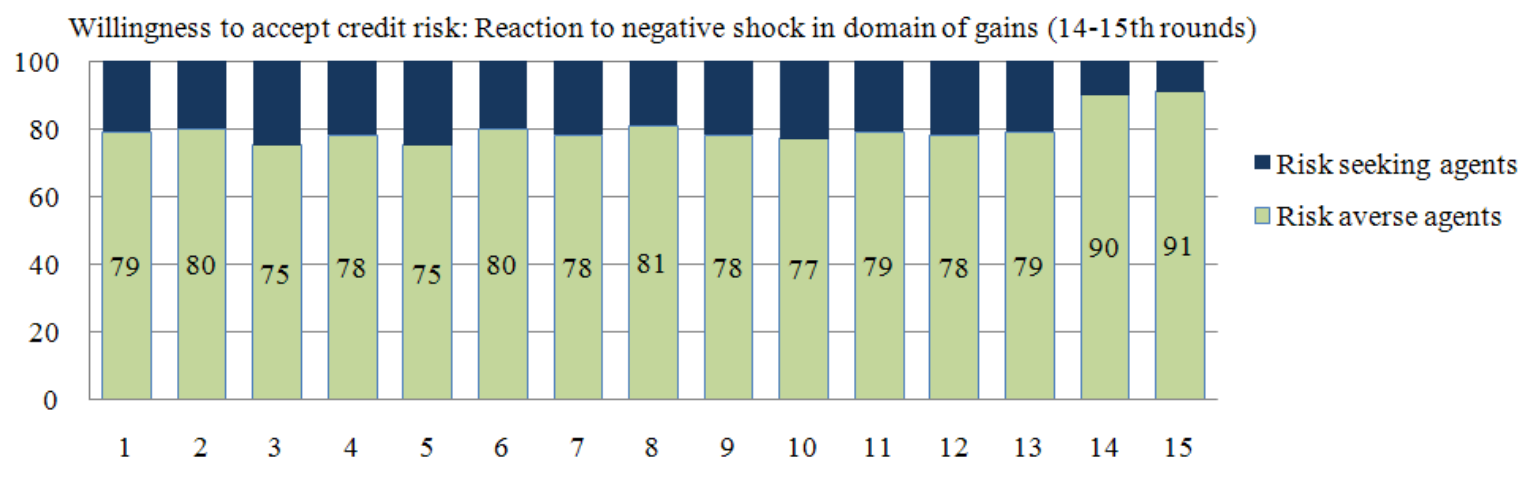

Fig. 1. Framing effect test in domain of gains

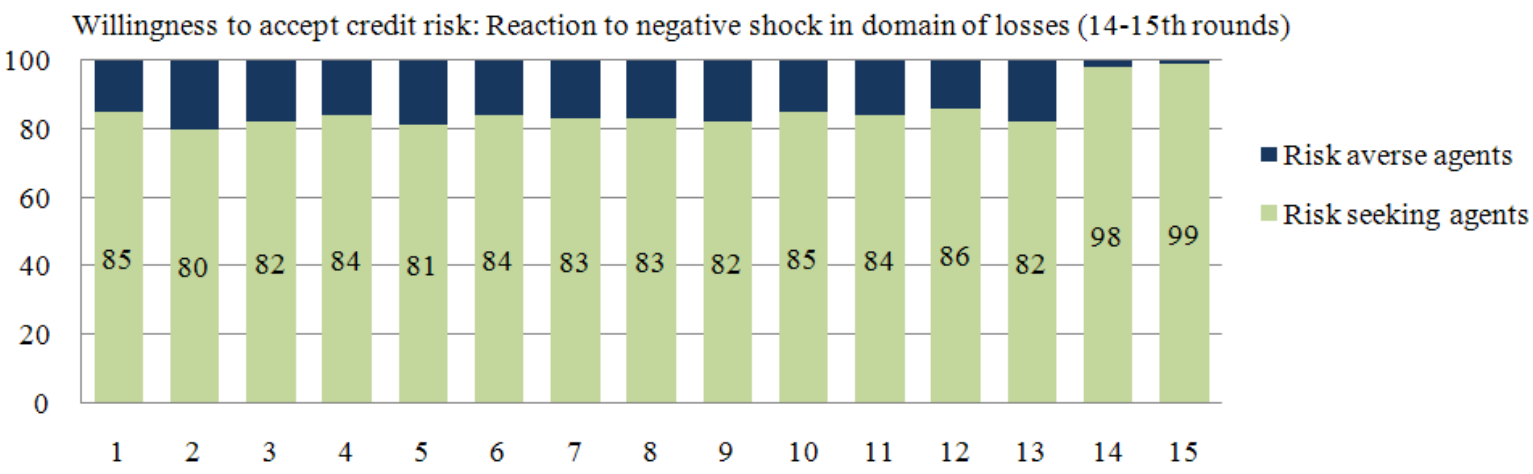

Fig. 2. Framing effect test in domain of losses 
Table 1. Results of framing effect test

\begin{tabular}{|c|c|c|c|c|}
\hline \multirow[b]{3}{*}{$1-13$ round } & \multicolumn{4}{|c|}{ Framing effect test } \\
\hline & \multicolumn{2}{|c|}{ Domain of gains } & \multicolumn{2}{|c|}{ Domain of losses } \\
\hline & $\begin{array}{l}\text { Risk averse } \\
\text { agents'share }\end{array}$ & $\begin{array}{l}\text { Risk seeking } \\
\text { agents'share }\end{array}$ & $\begin{array}{l}\text { Risk averse } \\
\text { agents'share }\end{array}$ & $\begin{array}{l}\text { Risk seeking } \\
\text { agents' share }\end{array}$ \\
\hline Average for 13 rounds & $78 \%$ & $22 \%$ & $83 \%$ & $17 \%$ \\
\hline
\end{tabular}

\section{CONCLUSION}

In the result of carried out research we came to conclusion that framing has a significant impact on the willingness to take risk. The key point of novelty is the consideration of this effect in the context not only of the credit market, but the credit cycle.

Firstly, we managed to reinforce the theoretical principles of the cumulative credit cycle model by empirical evidence that frame of losses has a significant impact on the attitude toward credit risk.

Secondly, we have provided arguments in favor of the impact of frame of losses on potential duration of credit crunch phase of the cycle. At the same time, unlike the cumulative model, we do not believe that the use of frame of losses can be considered as a sufficient explanation for the dynamics of the credit cycle: Many credit markets of the developing countries are not characterized by tough competition, dependence on short-term results and short-term market prices of bank shares. In other words, in some cases, credit market equilibrium is set in frame of gains.

Such heterogeneity is suggestive of the need for further research in this field with the aim of finding the mechanism of credit cyclicity and the formation of a unified theory of credit dynamics, which has the characteristics of descriptive and explanatory power not only for developed countries but also for developing economies.

\section{REFERENCES}

Berger, A. and G. Udell, 2004. The institutional memory hypothesis and the procyclicality of bank lending behavior. J. Financial Intermediation, 13: 459-495. DOI: $10.1016 /$ j.jfi.2004.06.006

Boulaalam, A., E.H. Nfaoui and O.E. Beqqal, 2013. Intelligent product based on mobile agent to accelerate the new product development process. J. Comput. Sci., 9: 856-865. DOI: $10.3844 /$ jcssp.2013.856.865

Burakov, D.V., 2011. The evolution of concepts of credit cyclicity. Transport Bus. Russia, 12: 148-149.
Burakov, D.V., 2012. Heterogeneity of the nature of credit cycles. Bus. Law, 3: 243-245.

Burakov, D.V., 2013. Exogenous credit cycles: An experimental study. World Applied Sci. J., 26: 733736. DOI: 10.5829/idosi.wasj.2013.26.06.13510

Geanakoplos, J., 2010. The Leverage Cycle. In: NBER Macroeconomics Annual 2009, Acemoglu, D., K. Rogoff and M. Woodford (Eds.), University of Chicago Press, pp: 1-65.

Haldane, A., A.G. Haldane and B.D Nelson, 2010. Curbing the Credit Cycle. Columbia University.

Kahneman, D. and A. Tversky, 2000. Choices, Values and Frames. 1st Edn., Cambridge University Press, ISBN-10: 0521627494, pp: 840.

Marti, M.S., 1996. Boundedly Rational Credit Cycles. 1st Edn., Universitat Pompeu Fabra, Barcelona, pp: 13.

Murugesan, P. and A. Shanmugam, 2013. Enhanced load balancing strategy in heterogeneous peer-to-peer networks. J. Comput. Sci., 9: 1197-1204. DOI: 10.3844/jcssp.2013.1197.1204

Pulakkazhy, S. and R.V.S. Balan, 2013. Data mining in banking and its applications-a review. J. Comput. Sci., $\quad$ 9: 1252-1259. DOI: 10.3844/jcssp.2013.1252.1259

Rajan, R., 1994. Why bank credit policies fluctuate: A theory and some evidence. Q. J. Econ., 109: 399441. DOI: $10.2307 / 2118468$

Rotheli, T.F., 2012. Boundedly rational banks' contribution to the credit cycle. J. Socio-Econ., 41: 730-737. DOI: 10.1016/j.socec.2012.07.005

Ruckes, M., 2004. Bank competition and credit standards. Rev. Financial Stud., 17: 1073-1102. DOI: $10.1093 / \mathrm{rfs} / \mathrm{hhh} 011$

Yahya, A.E.M. and M. Halaj, 2012. Uncertainty and its impact on the quality of measurement. Am. J. Eng. Applied Sci., 5: 114-118. DOI: 10.3844/ajeassp.2012.114.118 